\title{
Intestinal Absorption Mechanisms of Five Flavonoids from Malus hupehensis (Pamp.) Rehd. Extracts in Situ Single-Pass Intestinal Perfusion and in Vitro Caco-2 Cell Model
}

\section{Hui Yang}

Shaanxi University of Chinese Medicine

\section{Zhishu Tang}

Shaanxi University of Chinese Medicine

Jiangxue Cheng

Shaanxi University of Chinese Medicine

Jing Wang

Shaanxi University of Chinese Medicine

Junbo Zou

Shaanxi University of Chinese Medicine

Xiaofei Zhang

Shaanxi University of Chinese Medicine

Yajun Shi

Shaanxi University of Chinese

Dongyan Guo ( $\nabla$ xmc2051080@163.com )

Shaanxi University of Chinese Medicine

\section{Research}

Keywords: Malus hupehensis (Pamp.) Rehd. extracts, Flavonoids, Absorption, Caco-2 cell, Single-pass intestinal perfusion

Posted Date: September 2nd, 2020

DOl: https://doi.org/10.21203/rs.3.rs-67585/v1

License: (c) (1) This work is licensed under a Creative Commons Attribution 4.0 International License. Read Full License 


\section{Abstract}

Background: Previous studies have shown that Malus hupehensis (Pamp.) Rehd. extracts have antioxidant, anti-aging and other effects, its bioavailability is low, however its absorption mechanism is still unclear. To investigate the absorption properties of hyperin, quercitrin, phloridzin, quercetin, and phloretin in total flavonoids of Malus hupehensis (Pamp.) Rehd. Extracts.

Methods: In situ single-pass intestinal perfusion model and in vitro Caco-2 cell model were used in this study. The effects of concentration of the extract, administration time, temperature, different intestinal segments, paracellular pathway were analyzed, and the effect of efflux inhibitors, such as the P-gp inhibitor verapamil, the multidrug resistance protein2 (MRP2) inhibitor indomethacin, the breast cancer resistance protein (BCRP) inhibitor reserpine, on the transport were evaluated. As well as EDTA, a tight junction regulator, was studied.

Results: The results indicated that the jejunum was the optimal absorption intestine segment of quercitrin, phloridzin, and phloretin. And the greatest absorption intestine segment of quercetin was ileum. Furthermore, it was found that the absorption mechanisms of phloridzin in extract was involved in passive diffusion and the mediation of P-gp and MRP2 should not be neglected. The absorption mechanisms of quercetin and phloretin from extract involved active transport and were accompanied by the participation of efflux transporters, such as P-gp, MRP2 and BCRP. And also the paracellular pathway was involved in hyperin and quercitrin.

Conclusion: The absorption mechanisms of five flavonoids from Malus hupehensis (Pamp.) Rehd. extract are related to the concentration of the drugs, intestinal segments, and efflux protein.

\section{Background}

Malus hupehensis (Pamp.) Rehd., the family Rosaceae Malus Mill, is used both medicine and food [1], which is mainly distributed in western Hubei, northwestern Hunan [2]. The leaves of Malus hupehensis (Pamp.) Rehd. are often used for tea drinking in Hubei province [3, 4]. There are many chemical constituents in Malus hupehensis (Pamp.) Rehd., such as protein, polyphenols, flavonoids and trace elements, and so on[5]. Among them, flavonoids such as hyperin, quercitrin, phloridzin, quercetin, and phloretin were the primary bioactive constituents [5], which have the effect of nourishing the liver and stomach, digestion and transforming products [6]. Modern pharmacological studies have revealed many pharmacological effects of Malus hupehensis (Pamp.) Rehd.『such as anti-oxidation, anti-bacterial, antifibrosis, anti-hyperglycemic, anti-estrogen, anti-hypoxia, low temperature resistance and anti-fatigue [7-9]. It has been reported to be used clinically in treatment of chronic hepatitis, fatty liver, hyperglycemia, hyperlipidemia [6, 10-12].

Despite its rich pharmacological activity खbut low oral bioavailability of flavonoids, owing to low epithelial transport and extensive metabolism, is a major limitation for use of flavonoids as nutraceuticals [13]. Low bioavailability has been associated with flavonoid interactions at various stages of the absorption, 
distribution, metabolism and excretion, which were the important links in the development and evaluation of new drugs. And the absorption is one of the most important aspects. Generally, orally administered drugs are absorbed from the gastrointestinal tract, and intestinal permeability is considered to be a key determinant of the absorbed dose fraction, which directly affects bioavailability and bioequivalence, and will guide the design of oral drug products $[13,14]$. But there were no relative researches on the absorption of the Malus hupehensis (Pamp.) Rehd.. Until now, many absorption models, such as singlepass intestinal perfusion (SPIP) in situ, intestinal loops, isolated mucosa, and in vitro Caco-2 cell monolayers, everted sacs, are extensively used to investigate the intestinal absorption behavior of drugs [14-16]. Compared with other models, SPIP is simple and highly accurate in predicting the properties of intestinal absorption as the result of the intestinal manipulation is minimal, and normal blood supply is maintained $[17,18]$. It provides the best oral in situ conditions for studying drug absorption potential. In addition, as a vitro model, Caco-2 cell model expressed several active transport systems and marker enzymes [19-21], and was extensively used as a result of its morphological and functional similarities to the human small intestinal epithelium. Some transporters such as P-glycoprotein (P-gp), multidrug resistance-associated protein 1/2 (MRP1/2), breast cancer resistance protein (BCRP), organic cation transporters (OCTs), organic anion transporters (OATs), peptide transporters (PEPT) are expressed and active in Caco-2 cell monolayers $[22,23]$. And Caco-2 cell model has been approved by the FDA as a viable model for replicating human intestinal absorption [24, 25].

P-gp, MRP2, and BCRP, as efflux transporters, have been proven to be substrates for many flavonoids, affecting their oral bioavailability. Such as neobavaisoflavone is the substrate of P-gp and BCRP [26], ononin, baicalein, scutellarin, genistein, chamaechromone, glyceollin, and isoquercitrin are the substrate of MRP2 $[27,28]$. In order to understand the absorption mechanism clearly and estimate the interaction of the total flavonoids from Malus hupehensis (Pamp.) Rehd. extract, we applied the Caco-2 cell monolayer model in vitro and the single-pass intestinal perfusion in situ model to investigate the intestinal transport mechanism of hyperin, quercitrin, phloridzin, quercetin, and phloretin from extract.

\section{Materials And Methods}

\subsection{Chemicals and reagents}

Malus hupehensis (Pamp.) Rehd. extracts obtained by self-made. Phloridzin (purity $>98 \%$ ) was supplied by Sanxia University. Hyperin, quercetin, phloretin, quercitrin were obtained from Chengdu Pufei De Biotechnology Co., Ltd. Verapamil hydrochloride (purity $>98 \%$ ) was purchased from the China National Institute for the Control of Drugs (purity $>98 \%$ ). Indomethacin, reserpine, and EDTA (>98\%) came from Shanghai Yuanye Biotechnology Co., Ltd. Methanol and acetonitrile (HPLC grade) were purchased from Shanghai Adamas Company. Formic acid (HPLC grade) was provided by Tianjin Kermel Chemical Reagent factory.

2.2. Preparation of the total flavonoids from Malus hupehensis (Pamp.) Rehd. extracts 
The total flavonoids were extracted and purified from the leaves of Malus hupehensis (Pamp.) Rehd. according to the previous method of our research group [9, 29]. In brief, leaves were extracted twice by refluxing for 150 min with $70 \%$ ethanol $(1: 8, \mathrm{w} / \mathrm{v})$. The supernatant was collected and concentrated after centrifugation. Subsequently, total flavonoids were purified by using HPD 100 macroporous resin.

\subsection{The single-pass intestinal perfusion in situ model}

\subsubsection{Preparation of perfusion solution [16]}

A standard Krebs-Ringer (K-R) buffer was used, containing: $\mathrm{NaCl}, 7.8 \mathrm{~g} ; \mathrm{CaCl}_{2}, 0.37 \mathrm{~g} ; \mathrm{KCl}, 0.35 \mathrm{~g}$; $\mathrm{NaH}_{2} \mathrm{PO}_{4}, 0.32 \mathrm{~g} ; \mathrm{NaHCO}_{3}, 1.37 \mathrm{~g} ; \mathrm{MgCl}_{2}, 0.02 \mathrm{~g}$; glucose, $1.4 \mathrm{~g}$ (pH 7.3). The perfusion buffer was dissolved in $1 \mathrm{~L}$ of water, where $\mathrm{CaCl}_{2}$ was dissolved alone. All buffer solutions were prepared and used on the same day.

\subsubsection{In situ single-pass intestinal perfusion of Malus hupehensis (Pamp.) Rehd. extracts}

Male Sprague-Dawley rats $(220 \pm 30 \mathrm{~g})$ were used and supplied by the Experimental Animal Center of Xi'an Jiaotong University School of Medicine. The rats were raised under standard temperature, humidity, and light conditions, and had access to a standard rodent diet and water. The study was approved by the Ethical Committee of Shaanxi University of Chinese Medicine. Before surgery, animals were fasted for approximately $12 \mathrm{~h}$, but with free access to water. Rats were anesthetized by intraperitoneal injection of $10 \%$ urethane $\left(0.01 \mathrm{~mL} \cdot \mathrm{g}^{-1}\right)$, and fixed on the operating table. Then the abdominal cavity was opened. The duodenum, jejunum, ileum and colon, which were approximately $10 \mathrm{~cm}$, inserted the silicone tube and ligation carefully. Washed the contents of the intestines with physiological saline, and then equilibrated with a pre-warmed K-R solution and a drug-containing perfusate at $37^{\circ} \mathrm{C}$ for $30 \mathrm{~min}$ at a flow rate of 0.2 $\mathrm{mL} \cdot \mathrm{min}^{-1}$, respectively, to make the intestinal absorption stabilized. Subsequently, the effluent was collected every 15 min until $120 \mathrm{~min}$. The perfusate was collected and weighed. At last, cut off the intestines to measure the length and then sacrificed the rats. The effects of various concentrations (12.52, 25.04, and $50.08 \mathrm{mg} \cdot \mathrm{mL}^{-1}$ ) of Malus hupehensis (Pamp.) Rehd. extracts, different intestinal segments (duodenum, jejunum, ileum, and colon), various transporter inhibitors, including the P-gp inhibitor verapamil hydrochloride $\left(100 \mu \mathrm{mol} \cdot \mathrm{L}^{-1}\right)$, MRP2 inhibitor indomethacin $\left(50 \mu \mathrm{mol} \cdot \mathrm{L}^{-1}\right)$ and BCRP inhibitor reserpine $\left(50 \mu \mathrm{mol} \cdot \mathrm{L}^{-1}\right)$, and the tight junction regulator EDTA $\left(20 \mu \mathrm{mol} \cdot \mathrm{L}^{-1}\right)$ on the absorption of extracts were studied.

\subsubsection{HPLC analysis}

The column was a BDS HYPERSIL $\mathrm{C}_{18}$ column $(250 \mathrm{~mm} \times 4.6 \mathrm{~mm}, 5 \mu \mathrm{m})$. The temperature was set at $25^{\circ} \mathrm{C}$. The mobile phase was consisted of water with $0.1 \%$ phosphoric acid $(A)$ and acetonitrile (B) at a flow rate of $0.8 \mathrm{~mL} / \mathrm{min}$. The gradient program was as follows: $0-5 \mathrm{~min}: 5 \%-10 \% \mathrm{~B}, 5-10 \mathrm{~min}: 10 \%-20 \% \mathrm{~B}$, 10-20.3min: 20\%-18\%B, 20.3-23min: 18\%B, 23-29min: 18\%-38\%B, 29-30min: 38\%-40\%B, 30-40min: $40 \%-45 \% \mathrm{~B}$. The detection wavelength was $250 \mathrm{~nm}$. 


\subsubsection{Sample determination}

Intestinal perfusion samples were taken $200 \mu \mathrm{L}$ precisely, then added $800 \mu \mathrm{L}$ of methanol to vortex for 60 $\mathrm{s}$. After that, centrifuged at $13500 \mathrm{r} \cdot \mathrm{min}^{-1}$ for $10 \mathrm{~min}$, then filtered the supernatant through a $0.22 \mu \mathrm{m}$ microporous membrane and injected $10 \mu \mathrm{L}$ to analysis by HPLC.

\subsubsection{Data analysis}

Using the gravimetric formula, the apparent absorption coefficient ( ) of five flavonoids in the extract of Malus hupehensis (Pamp.) Rehd. extract was calculated. The formula is as follows:

$$
\mathrm{P}_{\text {app }}=\frac{-\mathrm{Q}_{\text {in }} \cdot \ln \left(\frac{\mathrm{C}_{\text {out }}}{\mathrm{C}_{\text {in }}} \cdot \frac{\mathrm{V}_{\text {out }}}{\mathrm{V}_{\text {in }}}\right)}{2 \pi \mathrm{rl}}
$$

where $V_{\text {in }}$ and $V_{\text {out }}$ are the volumes of the perfusate $(\mathrm{mL})$ entering and leaving the intestine, respectively; $\mathrm{C}_{\text {in }}$ and $\mathrm{C}_{\text {out }}$ are concentrations of the five flavonoids from extracts in the perfusate at the inlet and outlet, respectively; $Q_{\text {in }}$ is flow rate of the perfusion; I and $r$ are the length $(\mathrm{cm})$ and radius $(\mathrm{cm})$ of the perfused intestinal segment, respectively. All data were analyzed using SPSS 19.0 and expressed as the mean \pm $\operatorname{SD}(n=3)$. Differences between groups were calculated using unpaired t-test. When $p<0.05$, it was represented statistically significant.

\subsection{Caco-2 cell model}

\subsubsection{Cell culture materials}

IMDM medium and Hanks buffer (HBSS), PBS solution and penicillin- (100x) were from BOSTER; Trypsin$0.25 \%$ EDTA was purchased from Beijing Soleil Technologies Co., Ltd. Fetal calf serum (FCS) was purchased from Fetal bovine serum. DMSO and MTT came from Sigma; Millicell ERS-2 transmembrane cell resistance meter, Transwell chamber and 12-well Millicell plates were all purchased from Millipore, USA.

\subsubsection{Cytotoxicity of Malus hupehensis (Pamp.) Rehd. extracts for Caco-2 cells}

Cytotoxicity of Malus hupehensis (Pamp.) Rehd. extracts for Caco-2 cells was measured by MTT assay. Caco-2 cells were seeded into 96-well plates at a density of 5000 cells per well. After $24 \mathrm{~h}$ incubation, the cells were treated with increasing concentrations of Malus hupehensis (Pamp.) Rehd. extracts (40-180 $\left.\mu \mathrm{g} \cdot \mathrm{mL}^{-1}\right), 100 \mu \mathrm{L}$ of IMEM as a blank group. After $24 \mathrm{~h}, 48 \mathrm{~h}$, and $72 \mathrm{~h}$ incubation respectively, $10 \mu \mathrm{L}$ of $0.5 \%$ MTT was added to each well, and the plate was incubated at $37^{\circ} \mathrm{C}$ for $4 \mathrm{~h}$. Then, the supernatant was aspirated, and $150 \mu \mathrm{L}$ of DMSO was added to each well. Absorbance was measured at a wavelength of $490 \mathrm{~nm}$. The concentration of Malus hupehensis (Pamp.) Rehd. extracts was selected as a safe dose according to the cell survival rate $\geq 80 \%$. 


\subsubsection{Establishment of monolayer cell model}

Caco- 2 cells were cultured with DMEM containing $10 \%$ fetal bovine serum, $1 \% 100 \mathrm{IU} \cdot \mathrm{mL}^{-1}$ penicillin and $100 \mu \mathrm{g} \cdot \mathrm{mL}^{-1}$ streptomycin at $37^{\circ} \mathrm{C}$ in a humidified atmosphere of $5 \% \mathrm{CO}_{2}$. Then, cells were seeded into 12-well plates with Transwell culture inserts at a density of $1 \times 10^{5}$ cells per insert and cultured for 21 days. The medium was changed once every two days in the first week, and replaced with fresh medium every day after one week. The TEER value was used to monitor the integrity of a monolayer, that was used for transport studies with a TEER value above $200 \Omega \cdot \mathrm{cm}^{2}$. Differentiation of Caco-2 cells was checked on the 3rd, 7th, 14th, and 21 st days by observing cell morphology with light microscopy and determining the activity of alkaline phosphates with an assay kit.

\subsubsection{Transport studies}

Warmed HBSS $\left(37^{\circ} \mathrm{C}\right)$ was used as the transport buffer for bidirectional transport studies including absorption transport from the AP to the BL side and secretion transport from the BL to AP side. Before transport studies, the cell monolayer was washed twice with warm $\left(37^{\circ} \mathrm{C}\right) \mathrm{HBSS}$ and then the monolayers were incubated with the HBSS for $30 \mathrm{~min}$, after pre-incubation the incubation medium was aspirated, the concentration of Malus hupehensis (Pamp.) Rehd. extracts, which was dissolved in HBSS at 50, 100, and $150 \mu \mathrm{g} \cdot \mathrm{mL}^{-1}$, was loaded onto the AP $(0.5 \mathrm{~mL})$ or BL side $(1.5 \mathrm{~mL})$ and blank HBSS was added to the other side, respectively. After loading, a sample aliquot of $0.2 \mathrm{~mL}$ was taken from the $\mathrm{BL}$ or the AP receiver chamber at different time points $(30,60,90,120,150$ and $180 \mathrm{~min})$. After each sampling, an equal volume of HBSS was added to the receiver chamber to keep a volume constant. In this study, we explored the transportation of extract on the different concentration, different temperatures $\left(4^{\circ} \mathrm{C}\right.$ and $\left.37^{\circ} \mathrm{C}\right)$, different efflux inhibitors, including the P-gp inhibitors verapamil $\left(100 \mu \mathrm{mol} \cdot \mathrm{L}^{-1}\right)$, the MRP2 inhibitor indomethacin $\left(50 \mu \mathrm{mol} \cdot \mathrm{L}^{-1}\right)$ and the BCRP inhibitor reserpine $\left(50 \mu \mathrm{mol} \cdot \mathrm{L}^{-1}\right)$, and the tight junction regulator EDTA $\left(20 \mu \mathrm{mol} \cdot \mathrm{L}^{-1}\right)$. All samples were stored at $-20^{\circ} \mathrm{C}$ until assayed.

2.4.5. LC-MS/MS analysis of five flavonoids from Malus hupehensis (Pamp.) Rehd. extract

UPLC conditions Chromatographic separation was performed on a Sun Fire ${ }^{\mathrm{TM}} \mathrm{C}_{18}(150 \mathrm{~mm} \times 4.6 \mathrm{~mm} \rrbracket$ $5 \mu \mathrm{m})$. The column temperature was set at $35^{\circ} \mathrm{C}$. The mobile phase consisted of (A) $0.1 \%$ formic acid water and (B) acetonitrile. The gradient elution was set as: 10\%B (0-3 min), 25\% B (3.1-10 min), 10\%B (10.1-15 min囚at a flow rate of $0.8 \mathrm{~mL} \cdot \mathrm{min}^{-1}$ with a $5 \mu \mathrm{L}$ injection volume.

Mass spectrometry detection conditions ESI source was used as the source, the detection mode was negative ion detection with the multiple reaction-monitoring (MRM). The optimized instrument parameters were as follows: desolvation temperature was $550^{\circ} \mathrm{C}$; nebulizer was 50 psi; both nebulizer and blowback gas and collision gas were nitrogen; the declustering potential (DP), collision energy (CE), and collision cell exit potential (CXP) of the five flavonoids from Malus hupehensis (Pamp.) Rehd. extracts and bergenin (IS) are presented in Table 1. 


\subsubsection{Sample determination}

$10 \mu \mathrm{L}$ of $10 \mu \mathrm{g} \cdot \mathrm{mL}^{-1}$ internal standard was added to $200 \mu \mathrm{L}$ sample, then vortex and mix them. Centrifuge at $13500 \mathrm{r} \cdot \mathrm{min}^{-1}$ for $15 \mathrm{~min}$, and the supernatant was filtered through a $0.22 \mu \mathrm{m}$ microporous membrane. $5 \mu \mathrm{L}$ sample was injected to analysis and determine the concentrations of hyperin, quercitrin, phloridzin, quercetin and phloretin by LC-MS/MS.

\subsubsection{Data analysis}

The apparent absorption coefficient and ER value of five flavonoids from the extracts of Malus hupehensis (Pamp.) Rehd. were calculated. The formula is as follows:

$$
\mathrm{P}_{\mathrm{app}}=(\mathrm{dQ} / \mathrm{dt}) / \mathrm{AC}_{0} \quad \mathrm{ER}=\frac{\mathrm{P}_{\mathrm{app}(\mathrm{BL} \rightarrow \mathrm{AP})}}{\mathrm{P}_{\mathrm{app}(\mathrm{AP} \rightarrow \mathrm{BL})}}
$$

where $\mathrm{P}_{\mathrm{app}}$ (BL-AP) and $\mathrm{P}_{\mathrm{app}}$ (AP-BL) are the apparent permeability coefficients of the drug from the $\mathrm{BL}$ side to the AP side and from the AP side to the $B L$ side, respectively. The value of $d Q / d t$ is the cumulative transport rate of the compound on the receiver side. $A$ is the surface area of the membrane, and $\mathrm{C}_{0}$ is the initial drug concentration in the donor chamber. ER is efflux rate. All data were analyzed using SPSS 19.0 and presented as the mean $\pm S D(n=3)$. Differences between groups were calculated using unpaired t-test. When $p<0.05$, it was considered statistically significant.

\section{Results}

\subsection{Single-pass intestinal perfusion in situ model}

The absorption trends of five flavonoid extracts from Malus hupehensis (Pamp.) Rehd. at a concentration of $25.04 \mathrm{mg} \cdot \mathrm{mL}^{-1}$ were shown in Fig. 1. The Papp values of quercitrin, phloridzin, and phloretin were $(0.26 \pm 0.08) \times 10^{-5} \mathrm{~cm} \cdot \mathrm{s}^{-1},(0.40 \pm 0.11) \times 10^{-5} \mathrm{~cm} \cdot \mathrm{s}^{-1}$, and $(0.43 \pm 0.13) \times 10^{-5} \mathrm{~cm} \cdot \mathrm{s}^{-1}$ in the jejunum, respectively, and where the Papp values were significantly higher than in the colon. But the ileum may be the best absorption intestine segment of quercetin, that the Papp value was $(0.26 \pm 0.09) \times 10^{-5} \mathrm{~cm} \cdot \mathrm{s}^{-1}$. However, the Papp values of hyperin had no significantly different in the four intestinal segments, indicating that the intestinal segments may not affect the absorption of hyperin.

As shown in Fig. 2, the Papp values of phloridzin significantly increased from $(0.19 \pm 0.07) \times 10^{-5} \mathrm{~cm} \cdot \mathrm{s}^{-1}$ to $(0.65 \pm 0.22) \times 10^{-5} \mathrm{~cm} \cdot \mathrm{s}^{-1}$ in the jejunum with the concentration increase from $12.52 \mathrm{mg} \cdot \mathrm{mL}^{-1}$ to 50.08 $\mathrm{mg} \cdot \mathrm{mL}^{-1}$. For the phloretin, we found that the $P_{\text {app }}$ values increased from $(0.21 \pm 0.09) \times 10^{-5} \mathrm{~cm} \cdot \mathrm{s}^{-1}$ at the concentration of $12.52 \mathrm{mg} \cdot \mathrm{mL}^{-1}$ to $(0.43 \pm 0.13) \times 10^{-5} \mathrm{~cm} \cdot \mathrm{s}^{-1}$ at the concentration of $25.04 \mathrm{mg} \cdot \mathrm{mL}^{-1}$, with the concentration decreased to the $50.08 \mathrm{mg} \cdot \mathrm{mL}^{-1}$, the Papp values reduced to $(0.30 \pm 0.11) \times 10^{-5} \mathrm{~cm} \cdot \mathrm{s}^{-1}$, 
which had significant differences at the concentration of $25.04 \mathrm{mg} \cdot \mathrm{mL}^{-1}$. However, the Papp values of hyperin and quercitrin were increased with the concentration, but there were no significant changes.

Fig. 3 summarized the permeability coefficients of five flavonoids from extracts in the absence and presence of inhibitors. It was found in the Fig. $3 a$, that $P_{\text {app }}$ values of hyperin were $(0.10 \pm 0.03) \times 10^{-}$ ${ }^{5} \mathrm{~cm} \cdot \mathrm{s}^{-1},(0.08 \pm 0.03) \times 10^{-5} \mathrm{~cm} \cdot \mathrm{s}^{-1},(0.07 \pm 0.01) \times 10^{-5} \mathrm{~cm} \cdot \mathrm{s}^{-1}$, and $(0.05 \pm 0.01) \times 10^{-5} \mathrm{~cm} \cdot \mathrm{s}^{-1}$ in the duodenum, jejunum, ileum, and colon, respectively. When adding EDTA, a tight junction regulator, the Papp values increased to $(0.34 \pm 0.19) \times 10^{-5} \mathrm{~cm} \cdot \mathrm{s}^{-1},(0.23 \pm 0.09) \times 10^{-5} \mathrm{~cm} \cdot \mathrm{s}^{-1},(0.17 \pm 0.06) \times 10^{-5} \mathrm{~cm} \cdot \mathrm{s}^{-1}$, and $(0.12 \pm 0.05) \times 10^{-5} \mathrm{~cm} \cdot \mathrm{s}^{-1}$, respectively, indicating that EDTA can promote the absorption of hyperin. However, efflux inhibitors did not significantly affect the absorption of hyperin. In the Fig. 3b, we found that indomethacin or EDTA existed, the $\mathrm{P}_{\mathrm{app}}$ values of quercitrin were significantly increased in the intestine, suggesting that quercitrin was the substrate of the MRP2 and the mechanism of the paracellular may be involved. As shown in Fig. 3c, when phloridzin were combined with verapamil, a P-gp inhibitor, or indomethacin, a MRP2 inhibitor, the Papp values were significantly increased, speculating that P-gp and MRP2 may be the substrate of the phloridzin. The results of the effects of inhibitors on quercetin were shown in Fig. $3 \mathrm{~d}$. In the absence of inhibitors, the $P_{\text {app }}$ values were $(0.16 \pm 0.05) \times 10^{-}$ ${ }^{5} \mathrm{~cm} \cdot \mathrm{s}^{-1},(0.20 \pm 0.06) \times 10^{-5} \mathrm{~cm} \cdot \mathrm{s}^{-1},(0.26 \pm 0.09) \times 10^{-5} \mathrm{~cm} \cdot \mathrm{s}^{-1}$, and $(0.13 \pm 0.05) \times 10^{-5} \mathrm{~cm} \cdot \mathrm{s}^{-1}$ in the duodenum, jejunum, ileum, and colon, respectively. When using the verapamil, the $\mathrm{P}_{\text {app }}$ values were significantly increased to $(0.29 \pm 0.08) \times 10^{-5} \mathrm{~cm} \cdot \mathrm{s}^{-1},(0.36 \pm 0.11) \times 10^{-5} \mathrm{~cm} \cdot \mathrm{s}^{-1},(0.47 \pm 0.14) \times 10^{-5} \mathrm{~cm} \cdot \mathrm{s}^{-1}$, and $(0.23 \pm 0.11) \times 10^{-5} \mathrm{~cm} \cdot \mathrm{s}^{-1}$, in the four intestinal segments, respectively. The indomethacin make the $P_{\text {app }}$ of quercetin increase to $(0.35 \pm 0.12) \times 10^{-5} \mathrm{~cm} \cdot \mathrm{s}^{-1},(0.38 \pm 0.15) \times 10^{-5} \mathrm{~cm} \cdot \mathrm{s}^{-1},(0.51 \pm 0.19) \times 10^{-}$ ${ }^{5} \mathrm{~cm} \cdot \mathrm{s}^{-1}$, and $(0.28 \pm 0.09) \times 10^{-5} \mathrm{~cm} \cdot \mathrm{s}^{-1}$ compare with control group. The Papp values also significantly increased to $(0.25 \pm 0.12) \times 10^{-5} \mathrm{~cm} \cdot \mathrm{s}^{-1},(0.32 \pm 0.09) \times 10^{-5} \mathrm{~cm} \cdot \mathrm{s}^{-1},(0.41 \pm 0.18) \times 10^{-5} \mathrm{~cm} \cdot \mathrm{s}^{-1}$ in the presence of reserpine, a kind of BCRP inhibitor. As shown in Fig. 3e, the effect of the inhibitor on phloretin in the four intestinal segments is similar to that of quercetin. These results suggested that quercetin and phloretin may be the substrate of the P-gp, MRP2, and BCRP.

\subsection{Caco-2 cell model}

\subsubsection{The results of the cytotoxicity test}

The effects of extract on cell viability were examined by MTT assay, and the results are shown in Fig.4. The cell viability in the presence of $40-180 \mu \mathrm{g} \cdot \mathrm{mL}^{-1}$ extract was greater than $80 \%$. Therefore, transportation studies were carried out at concentrations of 50,100 , and $150 \mu \mathrm{g} \cdot \mathrm{mL}^{-1}$ extract.

\subsubsection{Results of the establishment of monolayer cell model}

Under the microscope, it was found that the Caco-2 cells were round or ovoid on the 3rd day. On the 7th day, the cells were fused into pieces. On the 14th day, the cells were uniform and dense. On the 21 st day, the cells have merged into a monolayer. Beyond that, the results of the activity of alkaline phosphates 
(AKP) were shown in Fig.5. On the 3rd day, the AKP ratio was only 1.58, so the activity was low. When the cell was cultured to 14th day, the ratio of AKP reached to 2.12 which was significantly increased; when cultured to 21 days, the ratio reached 2.71. In addition, when the cells were cultured for 21 days, the results of TEER values were shown in Fig.6, which was reached to $380.22 \Omega \cdot \mathrm{cm}^{2}$ and was greater than $200 \Omega \cdot \mathrm{cm}^{2}$. These results indicated that the cell monolayer was established successfully.

\subsubsection{The result of transport}

The effects of the concentration on the transport of five flavonoids from Malus hupehensis (Pamp.) Rehd. extracts were shown in Fig. 7. It was found that the $P_{\text {app }}$ values increased from $(0.08 \pm 0.01) \times 10^{-6}$ $\mathrm{cm} \cdot \mathrm{s}^{-1}$ to $(0.25 \pm 0.03) \times 10^{-6} \mathrm{~cm} \cdot \mathrm{s}^{-1} \otimes$ from $(1.98 \pm 0.12) \times 10^{-6} \mathrm{~cm} \cdot \mathrm{s}^{-1}$ to $(4.13 \pm 0.12) \times 10^{-6} \mathrm{~cm} \cdot \mathrm{s}^{-1}$ and from $(1.52 \pm 0.04) \times 10^{-6} \mathrm{~cm} \cdot \mathrm{s}^{-1}$ to $(2.39 \pm 0.03) \times 10^{-6} \mathrm{~cm} \cdot \mathrm{s}^{-1}$ in the AP-BL direction of hyperin囚phloridzin and phloretin with the increase of concentration, respectively. However, the $\mathrm{P}_{\mathrm{app}}$ values of quercitrin were increased with the concentration increase from $50 \mu \mathrm{g} \cdot \mathrm{mL}^{-1}$ to $100 \mu \mathrm{g} \cdot \mathrm{mL}^{-1}$, but the Papp values of quercitrin reduced with the concentration increase from $100 \mu \mathrm{g} \cdot \mathrm{mL}^{-1}$ to $150 \mu \mathrm{g} \cdot \mathrm{mL}^{-1}$. About quercetin, there were no significant changes as its concentration increased. The results of the ER about five flavonoids from extract were shown in Table 2. At three concentrations, the ER of hyperin and phloridzin are both less than 1.5, the ER of quercitrin, quercetin, and phloretin are higher than 1.5 , suggesting that quercitrin, quercetin, and phloretin may be involved in active transport, and there may be involvement of efflux transporters.

The effect of temperature on the transport of five flavonoids from extract in the AP-BL at the concentration of $100 \mu \mathrm{g} \cdot \mathrm{mL}^{-1}$ was shown in Fig. 8. It was found that the $\mathrm{P}_{\mathrm{app}}$ (AP-BL) value of phloridzin and phloretin were significantly decreased from $(2.79 \pm 0.24) \times 10^{-6} \mathrm{~cm} \cdot \mathrm{s}^{-1}$ at $37^{\circ} \mathrm{C}$ to $(1.79 \pm 0.22) \times 10^{-}$ ${ }^{6} \mathrm{~cm} \cdot \mathrm{s}^{-1}$ at $4^{\circ} \mathrm{C}$ and from $(1.83 \pm 0.17) \times 10^{-6} \mathrm{~cm} \cdot \mathrm{s}^{-1}$ at $37^{\circ} \mathrm{C}$ to $(1.32 \pm 0.20) \times 10^{-6} \mathrm{~cm} \cdot \mathrm{s}^{-1}$ at $4^{\circ} \mathrm{C}$. And there were no significantly different about hyperin, quercitrin, and quercetin with temperature. These results suggested that the transport of phloridzin and phloretin were affected by the temperature.

The effect of several inhibitors on the transport of five flavonoids was shown in Fig. 9. Compared with the control group, the Papp values of phloretin were significantly increased after adding verapamil $(p<0.05)$, indicating phloretin is the P-gp substrates; after indomethacin was added, the $P_{\text {app }}$ values of quercitrin, quercetin, and phloretin from AP to BL was increased significantly $(p<0.05)$, it was speculated that the quercitrin, quercetin, and phloretin were the substrates of MPR2; for the addition of reserpine, the Papp values of quercetin was increased significantly $(p<0.05)$ in the direction of AP-BL, suggesting that the quercetin was the substrates of BCRP. After adding EDTA, the Papp values of hyperin and quercitrin were significantly increased $(p<0.05)$, indicating that the EDTA can promote the transport of hyperin and quercitrin, so these may involve the transport mechanism of paracellular.

\section{Discussion}


In this study, the intestinal absorption mechanisms of hyperin, quercitrin, phloridzin, quercetin and phloretin in Malus hupehensis (Pamp.) Rehd. extracts were investigated by using the Caco-2 cell model and single-pass intestinal perfusion model. It was known that the bioavailability and pharmacological effects are related to the interaction of flavonoids or other ingredients in the extract in the intestinal absorption, in which the $A B C$ transporters and related enzyme systems played an important role [28].

In situ single-pass intestinal perfusion model, it could be inferred that site-dependence occurred in the intestinal absorption process of five flavonoids from the extract. Such as the best intestinal absorption of quercitrin, phloridzin, and phloretin was jejunum, and the ileum may be the best absorption intestine segment of quercetin. These results were similar to the result of related literatures, those reported that quercetin, from Hippophaë rhamnoides extracts, has the best absorption effect in the ileum [14], and the best absorption intestinal segments of the phloridzin monomer is the jejunum [30]. These results were possibly related to the $\mathrm{pK}_{\mathrm{a}}$ of the drug, the degree of dissociation, $\mathrm{pH}$ of the intestinal fluid, the surface area of intestine mucosa, the thickness of mucous layers, the activities of enzyme, the flow rate of capillary blood, the components of membrane, the resistance of tight junction, and the distribution of efflux transporters and uptake transporters in the different intestinal [31, 32]. In addition, we also found the $P_{\text {app }}$ values of the hyperin quercitrin, and quercetin were lower than $3 \times 10^{-6} \mathrm{~cm} \cdot \mathrm{s}^{-1}$ in the four segments, however the $P_{\text {app }}$ values of the phloridzin and phloretin were between $3 \times 10^{-6} \mathrm{~cm} \cdot \mathrm{s}^{-1}$ and $2 \times 10^{-5} \mathrm{~cm} \cdot \mathrm{s}^{-1}$ in jejunum. It has been reported in the literature that at a $P_{\text {app }}$ value of $<3 \times 10^{-6} \mathrm{~cm} \cdot \mathrm{s}^{-1}$, the drug is not well absorbed, whereas at a $\mathrm{P}_{\text {app }}$ value of $>2 \times 10^{-5} \mathrm{~cm} \cdot \mathrm{s}^{-1}$, the drug is well absorbed [33, 34]. Therefore, our data showed that hyperin quercitrin, and quercetin absorbed poorly, but the phloridzin and phloretin absorbed better in jejunum. Other than these, P-gp, MRP2, and BCRP, as ABC transporters, are distributed in the intestine. These efflux proteins located in the apical membrane may drive compounds back into the intestinal lumen from inside the cell, preventing their absorption into blood. This efflux mechanism plays a key role in limiting the absorption and accumulation of drugs [35]. By studying different efflux protein inhibitors, it was found that the efflux proteins involved in the single-pass intestinal perfusion of the five flavonoids, which means quercitrin is the substrate for MRP2, phloridzin is the substrate for P-gp and MRP2, as well as quercetin and phloretin are the substrate for P-gp, MRP2, and BCRP. EDTA, as a regulator to open tight junctions, can react with $\mathrm{Ca}^{2+}$ and $\mathrm{Mg}^{2+}$ ions in the mucus layer to change the viscosity of the mucus, further to improve the permeability of the drug and enhance the absorption and bioavailability during paracellelar transport of drugs [36, 37]. In this study, it was found that paracellular pathway was involved in hyperin and quercitrin.

In the Caco-2 cell model presented similar results from single-pass intestinal perfusion model. In the whole transmembrane transport experiments, the integrity is extremely critical. Hence, prior to the transport experiments, we measured the TEER values of Caco-2 cell monolayers and the activity of alkaline phosphates. The TEER value is one of the indicators for detecting the integrity of the Caco-2 cell monolayer model. The more complete the monolayer model, the greater the TEER value formed. It is generally believed that when TEER $>200 \Omega \cdot \mathrm{cm}^{2}$, a cell monolayer model has been formed. Alkaline phosphatase is a marker enzyme of the brush border of the small intestine epithelium, which can 
differentiate during the formation of Caco-2 cell monolayer. By measuring the alkaline phosphatase activity of Caco-2 cells at various stages, the biochemical characteristics and cell polarity of Caco- 2 cells can be reflected [38]. In this study, The TEER values were above $300 \Omega \cdot \mathrm{cm}^{2}$, indicating that the cells formed a dense monolayer. Besides, when the cells monolayer cultured to 21 days, the AKP ratio of AP/BL reached 2.71, which was proved that the distribution of alkaline phosphatase is asymmetric and obvious polarization phenomenon was occurred. In the transport studies, it was found that there was a significant difference between the high and low concentrations of $\mathrm{P}_{\text {app }}$ about the hyperin, phloridzin, and phloretin $(p<0.05)$, and its ER $\otimes 1.0$, so it can be speculated that the absorption mechanism of hyperin and phloridzin is mainly passive transport and involved active transport. The ER values of quercitrin, quercetin, and phloretin were higher than 1.5, indicating that the transport of quercitrin, quercetin and phloretin may involve active transport or some efflux transporters were participated. Since the temperature can affect the energy supply during active transport, as well as the cell activity, the speed of movement of intestinal villi on the AP side, and the gap between cells [39], $P_{\text {app }}$ values were studied at different temperatures. The $\mathrm{P}_{\text {app }}$ value of phloridzin and phloretin were found to be significantly higher at $37^{\circ} \mathrm{C}$ than at $4^{\circ} \mathrm{C}$, suggesting that the absorption process of phloridzin and phloretin may be affected by the temperature, which speculated that an active transport process may be involved. In addition, we observed that $P_{\text {app }}$ values of five flavonoids were higher than $0.1 \times 10^{-6} \mathrm{~cm} \cdot \mathrm{s}^{-1}$ at three concentrations. It has been reported that $P_{\text {app }}$ values of drugs are above $1.0 \times 10^{-6} \mathrm{~cm} \cdot \mathrm{s}^{-1}$ that are completely absorbed in the intestine. Drugs whose absorption is more than $1 \%$ but less than $100 \%$ have $P_{\text {app }}$ values of $0.1-1.0 \times 10^{-6}$ $\mathrm{cm} \cdot \mathrm{s}^{-1}$, while drugs whose absorption is less than $1 \%$ have $P_{\text {app }}$ values of less than or equal to $1.0 \times 10^{-7}$ $\mathrm{cm} \cdot \mathrm{s}^{-1}[40]$. Therefore, it can be considered that the absorption of five flavonoids in the extract is between $1 \%$ and $100 \%$. When studying the effects of verapamil, a P-gp inhibitor, on the absorption of extracts, it was found that $P_{a p p}$ values of phloretin were significantly higher than those when no inhibitor was added, suggesting that the phloretin was the substrate of the P-gp. It has been reported that quercetin monomer is approved not to be a substrate of P-gp, which is consistent with our results [41]. Meanwhile, it was showed a significant increase in the absorption of quercitrin, quercetin and phloretin in the presence of a MRP2 inhibitor, indicating that quercitrin, quercetin and phloretin were the substrate of MRP2, which was in agreement with literatures these reported that quercetin have a comparably strong affinity to MRPs [14, 41]. One possible reason was that flavonoids aglycone such as isorhamnetin, quercetin, and kaempferol could be transformed into sulfate and glucuronide conjugates after absorption in the intestine and then MRP2 could mediate the transport of their conjugated compounds [14]. However, a strange phenomenon was observed from Fig.9, indomethacin and reserpine reduced the Papp values of phloridzin. This may be due to the bi-directional regulation of efflux protein by other compounds in Malus hupehensis (Pamp.) Rehd. For example, the relative protein and mRNA intensities of MRP2 were down-regulated by $4.5 \mu \mathrm{g} /$ $\mathrm{mL}$ of isorhamnetin, but up-regulated by $18 \mu \mathrm{g} / \mathrm{ml}$ of isorhamnetin. This bi-directional regulation may be related to some key receptors of MRP2, which needs to be explored in future research [28]. Besides, we found EDTA can open the tight junction to promote the absorption of the hyperin and quercitrin, speculating that the paracellular pathway may be involved in hyperin and quercitrin. This is consistent with the results of single-pass intestinal perfusion model. 
In short, the absorption mechanisms of five flavonoids from Malus hupehensis (Pamp.) Rehd. extracts are related to the concentration of the drugs, intestinal segments, and efflux protein. In addition, different absorption mechanisms of five flavonoids from extracts may be due to their different structure[42], enterohepatic circulation and intestinal flora[14]. Such as the absorption processes of three flavonoids (isorhamnetin, quercetin, and kaempferol) from Hippophaë rhamnoides extracts involves enterohepatic circulation and intestinal flora[14]. Furthermore, the interaction of various components in the extracts may also affect the absorption of the drug. Therefore, further study of the absorption mechanism of extract is not negligible.

\section{Conclusion}

In this present study, the effects of the different concentrations, time, temperature, tight junction regulators, and transporter inhibitors on the transport of five flavonoids from Malusa hupehensis (Pamp.) Rehd. extracts were investigated by the Caco- 2 cell model in vitro and the single-pass intestinal perfusion in situ. We found that the transport mechanisms of hyperin may involve passive transport and paracellular pathway, quercitrin may involve active transport and paracellular pathway, as well as the MRP2 was involved, phloridzin may involve passive transport and be substrate for P-gp and MRP2, and quercetin and phloretin may involve active transport and the substrate for P-gp, MRP2, and BCRP. In addition, the dependent of the intestinal site is also an indispensable role for the absorption of the five flavonoids.

\section{Declarations}

\section{Acknowledgements}

The authors thank the teachers of the Shaanxi University of Chinese Medicine for their guidance on the experiments.

\section{Authors' contributions}

Dongyan Guo and Zhishu Tang designed the research. Hui Yang completed the experiments. Jing wang and Jiangxue Cheng analyzed the data. Junbo Zou, Xiaofei Zhang ang Yajun Shi wrote the manuscript. Dongyan Duo Reviewed the manuscript. All authors read and approved the final manuscript.

\section{Availability of data and materials}

All data generated or analyzed during this study are included in this published article.

\section{Consent for publication}

Not applicable.

\section{Ethics approval and consent to participate}


The study was approved by the Ethical Committee of Shaanxi University of Chinese Medicine.

\section{Funding}

This work was supported by the Scientific research project of Education Department of Shaanxi Provincial Government (No.15JF015), National Natural Science Foundation of China (No.81202905), and Subject Innovation Team of Shaanxi University of Chinese Medicine (No.2019-YL11).

\section{Declaration of Competing Interest}

The authors declare no conflict of interest.

\section{References}

1. Tianyan F, Yunzhi W, Jigang Z, Gaigai D, Qiaoyin Z, Kun Z. Protective effect of lutcin on acute alcoholic liver injury in mice. Pharmacology Clinics of Chinese Materia Medica. 2012;28:72-6.

2. Dongyan G, Jin L, Yanqiong S, Yunzhi W. Study on the flavon ingredients of Malus hupehensis. Journal of Chinese Medicinal Materials. 2011;34:1026-9.

3. Liu, Ding T. Study on the tea drink and its stability in Malus hupehensis (Pamp.) Rehd. Journal of Hubei Agricultural College. 2004;24:326-7.

4. Yunzhi W, Yuanbing Y. Study on the quality of Malus hupehensis (Pamp.) Rehd. Beverage Food research development. 2002;23:59-61.

5. Yan L, Kaiyan L. Research progress of chemical constituents and pharmacological activities of Malus hupehensis. Chinese Journal of Experimental Formulaology. 2016;22:226-9.

6. Gong P, Yang M, He K, Sun Z, Liu Q. Therapeutic effect of Malus Hupehensis Rehd. leaves on type 2 diabetes. Practical diabetes journal. 2011;7:34-5.

7. Qing D, Dabing R, Yanhua Q, Yizeng L. Separation and preparation of flavonoids from leaves of Malus Hupehensis Rehd. by two-dimensional high speed countercurrent chromatography. Jiangxi Chemical Industry 2014:115-121.

8. Zuming L, Lihua K, Ling Y, Qing W, Chaoming H, Zulian X, Keyi Q, Jianrong L. Therapeutic effect of Malus hupehensis (Pamp.) Rehd. leaf decoction on HSV-1 viral conjunctivitis. Medical guide. 2014;33:862-5.

9. Liu, Guo D, Fan Y, Sun J, Cheng J, Shi Y. Experimental study on the antioxidant activity of Malus hupehensis (Pamp.) Rehd extracts in vitro and in vivo. J Cell Biochem. 2019;120:11878-89.

10. Cao D, Xue B, Huang W, Wang Y, Wang H, Zhou J, Zou K, Wang Y. Effect of total flavonoids from Malus hupehensis (Pamp.) Rehd. on osteoporosis in ovariectomized rats. Chinese medicine pharmacology and clinical 2011:56-59.

11. Youqin D, Tianyan F, Gaigai D, Ying L, Yunzhi W. Inhibition of total flavonoids from Malus Hupehensis Rehd. leaves on hepatic fibrosis in mice infected with Schistosoma japonicum. Chinese Journal of Schistosomiasis Control. 2011;23:551-4 + 599. 
12. Feng T, Wang Y, Zhou J, Deng G, Zhang Q, Zou K. Study on the effect of total flavonoids from Malus Hupehensis Rehd. on liver fibrosis induced by $\mathrm{CCl} 4$ in rats.

13. Chinese medicine pharmacology. and clinical 2012:71-75.

14. Stappaerts J, Brouwers J, Annaert P, Augustijns P. In situ perfusion in rodents to explore intestinal drug absorption: challenges and opportunities. Int J Pharm. 2015;478:665-81.

15. Xin L, Liu XH, Yang J, Shen HY, Ji G, Shi XF, Xie Y. The intestinal absorption properties of flavonoids in Hippophae rhamnoides extracts by an in situ single-pass intestinal perfusion model. J Asian Nat Prod Res. 2017;21:1-14.

16. Hewei L, Ling D, Yang L, Gang W, Lei Z, Yanjiang Q. Comparison of two approaches of intestinal absorption by puerarin. J Pharmacol Toxicol Methods. 2014;70:6-11.

17. Zhai L, Shi J, Xu W, Heinrich M, Wang J, Deng W. Ex vivo and in situ evaluation of 'Dispelling-Wind' chinese medicine herb-drugs on intestinal absorption of chlorogenic acid. Phytother Res. 2015;29:1974-81.

18. Lennernas $\mathrm{H}$. Regional intestinal drug permeation: biopharmaceutics and drug development. Eur $\mathrm{J}$ Pharm Sci. 2014;57:333-41.

19. Escribano E, Sala XG, Salamanca J, Navarro CR, Regue JQ. Single-pass intestinal perfusion to establish the intestinal permeability of model drugs in mouse. Int J Pharm. 2012;436:472-7.

20. Borlak J, Zwadlo C. Expression of drug-metabolizing enzymes, nuclear transcription factors and ABC transporters in Caco-2 cells. Xenobiotica. 2003;33:927-43.

21. Fossati L, Dechaume R, Hardillier E, Chevillon D, Prevost C, Bolze S, Maubon N. Use of simulated intestinal fluid for Caco-2 permeability assay of lipophilic drugs. Int J Pharm. 2008;360:148-55.

22. Maubon N, Le Vee M, Fossati L, Audry M, Le Ferrec E, Bolze S, Fardel O. Analysis of drug transporter expression in human intestinal Caco-2 cells by real-time PCR. Fundam Clin Pharmacol. 2007;21:659-63.

23. Estudante M, Morais JG, Soveral G, Benet LZ. Intestinal drug transporters: an overview. Adv Drug Deliv Rev. 2013;65:1340-56.

24. Xuelian L, Jiaxin W, Jing W, Sen L, Yueliu D, Ling D. Effect of different concentrations of Gegen Qinlian decoction on expression of P-glycoprotein and multi-drug resistance protein transporter in Caco-2 cells. China Journal of Chinese Materia Medica. 2018;43:3135-9.

25. Chen, Wang Y, Zhou J, Gao X, Qu D, Liu C. Study on the mechanism of intestinal absorption of epimedins A, B and C in the Caco-2 cell model. Molecules. 2014;19:686-98.

26. Li ZL, Zhou L, Wo SK, Lin G, Zuo Z. Comparison of intestinal absorption and disposition of structurally similar bioactive flavones in Radix Scutellariae. AAPS J. 2012;14:23-34.

27. Xiaokun X, Zhiyong C, Zhuoqing L, Yimin Z, Liping L, Qiang Z, Zijia Z. Absorption mechanism of neobavaisoflavone in Caco-2 cell monolayer mode. China Journal of Chinese Materia Medica. 2016;41:2922-6. 
28. Luo LY, Fan MX, Zhao HY, Li MX, Wu X, Gao WY. Pharmacokinetics and bioavailability of the isoflavones formononetin and ononin and their in vitro absorption in ussing chamber and Caco-2 cell models. J Agric Food Chem. 2018;66:2917-24.

29. Xiao Y, Xin L, Li L, Li G, Shi X, Ji G, Mi J, Xie Y. Quercetin and kaempferol increase the intestinal absorption of isorhamnetin coexisting in Elaeagnus rhamnoides (L.) A. Nelson (Elaeagnaceae) extracts via regulating multidrug resistance-associated protein 2. Phytomedicine. 2019;53:154-62.

30. Guo D, Dang J, Yang H, Fan Y, Cheng J, Shi Y, Zhang X, Zou J. Simultaneous determination of four flavonoids in rat plasma after oral administration of Malus hupehensis (Pamp.) Rehd. extracts by UPLC-MS/MS and its application to a pharmacokinetics study. J Pharm Biomed Anal. 2020;177:112869.

31. Bingtao Z, Dong G, Yajun S, Yu F, Weiping Y, Jia L. Intestinal absorption characteristics of phlorizin in rats. China Journal of Chinese Materia Medica. 2016;41:2527-31.

32. Pang K. Modeling of intestinal drug absorption: roles of transporters and metabolic enzymes (for the Gillette Review Series). Drug Metab Dispos. 2003;31:1507-19.

33. Jiang CP, He X, Yang XL, Zhang SL, Li H, Song ZJ, Zhang CF, Yang ZL, Li P. Intestinal absorptive transport of Genkwanin from Flos genkwa using a single-pass intestinal perfusion rat model. Am J Chin Med. 2014;42:349-59.

34. Wang K, Zhang Y. Absorption mechanism of three curcumin constituents through in situ intestinal perfusion method. Braz J Med Biol Res. 2017;50:e6353.

35. Wenli Y, Zhaosheng H, Xiaohui Z, Ziming Z, Xuejun H, Tieliang D. Single-pass perfusion method for the study of Curcumin absorption in rats. Pharmaceutical Today. 2012;22:137-41.

36. Chan LM, Lowes S, Hirst BH. The ABCs of drug transport in intestine and liver: efflux proteins limiting drug absorption and bioavailability. Eur J Pharm Sci. 2004;21:25-51.

37. Caifu X: Study on absorption and metabolism of flavonoids from Abelmoschus manihot. Nanjing University of Chinese Medicine, 2011.

38. Hong L, Jie L, Lu L, Yichuan Z, Yili L, Xiaoli Z, Peng Y, Manna Z, Weifeng Y, Shen Q. Elucidation of the intestinal absorption mechanism of Celastrol using the Caco-2 cell transwell model. Planta Med. 2016;82:1202-7.

39. Sun X, Luo Y. Establishment of Caco-2 cell monolayer model. Drug Evaluation. 2015;12:33-5 + 39 .

40. Anguo W, Zeng B, Huang M-Q, Li S-M, Chen J-N, Lai X-P. The absorption and transport of magnolol in Caco-2 cell model. 2012.

41. Zhang B, Zhu XM, Hu JN, Ye H, Luo T, Liu XR, Li HY, Li W, Zheng YN, Deng ZY. Absorption mechanism of ginsenoside compound $\mathrm{K}$ and its butyl and octyl ester prodrugs in Caco-2 cells. J Agric Food Chem. 2012;60:10278-84.

42. Naitchabane M, Al Ahmad A, Peluso J, Muller CD, Ubeaud G. Quercetin and naringenin transport across human intestinal Caco-2 cells. J Pharm Pharmacol. 2009;61:1473-83. 
43. Fang Y, Cao W, Xia M, Pan S, Xu X. Study of structure and permeability relationship of flavonoids in Caco-2 Cells. Nutrients. 2017;9:1301.

\section{Tables}

Table1.Optimized multiple reaction monitoring parameters for the detection of main index components and internal standard.

\begin{tabular}{|llllll|}
\hline compounds & $\begin{array}{l}\text { Precursor ion } \\
(\mathrm{m} / \mathrm{z})\end{array}$ & Product ion $(\mathrm{m} / \mathrm{z})$ & $\mathrm{DP}(\mathrm{V})$ & $\mathrm{CE}(\mathrm{V})$ & $\mathrm{CXP}(\mathrm{V})$ \\
\hline Hyperin & 463.0 & 300.0 & -92.8 & -30.7 & -9.05 \\
\hline Quercitrin & 447.0 & 301.1 & -87.9 & -30.0 & -9.00 \\
\hline Phloridzin & 435.2 & 273.0 & -89.0 & -20.0 & -7.00 \\
\hline Quercetin & 301.0 & 151.0 & -86.7 & -30.0 & -9.00 \\
\hline Phloretin & 273.1 & 166.7 & -88.3 & -23.3 & -12.7 \\
\hline Bergenin & 327.0 & 192.0 & -55.5 & -32.0 & -8.37 \\
\hline
\end{tabular}

Table 2. The ratio of efflux (ER) of five flavonoids at different concentrations. Data represent mean \pm SD $(\mathrm{n}=3) .{ }^{*} p<0.05$, significantly different from low concentration, ${ }^{*} p<0.05$, significantly different from high concentration.

\begin{tabular}{|llllll|}
\cline { 1 - 4 } $\begin{array}{l}\text { Concentration } \\
\left(\mu \mathrm{g} \cdot \mathrm{mL}^{-1}\right)\end{array}$ & & & & & \\
\cline { 1 - 5 } Hyperin & Quercitrin & Phloridzin & Quercetin & Phloretin & \\
\cline { 1 - 2 } 50 & $1.38 \pm 0.39$ & $3.31 \pm 0.41$ & $1.40 \pm 0.52$ & $2.10 \pm 0.12$ & $1.70 \pm 0.02$ \\
\hline 100 & $1.24 \pm 0.21$ & $3.88 \pm 1.10^{\#}$ & $1.48 \pm 0.23$ & $1.69 \pm 0.10$ & $3.89 \pm 0.12^{\star}$ \\
\hline 150 & $1.20 \pm 0.40$ & $2.35 \pm 0.70$ & $1.16 \pm 0.10$ & $1.79 \pm 0.37$ & $1.67 \pm 0.46$ \\
\hline
\end{tabular}

\section{Supplementary Files}

This is a list of supplementary files associated with this preprint. Click to download.

- 2020710Supplementalmaterials.docx 